\title{
ANALISIS PENYEBAB TURUNNYA TEMPERATUR PADA RUANG PENDINGIN MAKANAN DI MT. BAUHINIA
}

\author{
Yulian Harjuansyah ${ }^{\mathrm{a}}$, Abdi Seno ${ }^{\mathrm{b}}$, Okvita Wahyuni ${ }^{\mathrm{c}}$ \\ ${ }^{a}$ Taruna Progam Studi Teknika PIP Semarang \\ ${ }^{\mathrm{b}}$ Dosen Progam Studi Teknika PIP Semarang \\ ${ }^{c}$ Dosen Progam Studi KALK PIP Semarang \\ * email: yulianharju13@gmail.com
}

\begin{abstract}
ABSTRAK
Mesin pendingin makanan di kapal MT. Bauhinia digunakan untuk menjaga ketahanan pada bahan makanan, agar tetap segar dan terjaga kualitasnya. Dengan suhu ruangan pendingin yang terkontrol akan dapat menghambat perkembangan bakteri dalam bahan makanan yang dapat menyebabkan terjadinya pembusukan. Dengan ketentuan untuk menyimpan sayur dan buah agar tetap segar diperlukan suhu ruangan antara $4^{\circ} \mathrm{C}$ sampai $10^{\circ} \mathrm{C}$ dan untuk ruangan daging dan ikan harus mampu menyediakan suhu antara $-12^{\circ} \mathrm{C}$ sampai $-18^{0} \mathrm{C}$. Dengan mencari faktor-faktor, dampak dan juga upaya dari turunnya temperatur pada ruang pendingin makanan. Dengan menggunakan metode fault tree analysis yaitu metode membuat pohon kesalahan sebagai pencari penyebab terjadinya permasalahan. Metode pengumpulan data yang digunakan adalah dengan cara observasi, wawancara, studi pustaka, dan studi dokumentasi. Teknik analisis data digunakan antara lain adalah reduksi data, penyajian data dan menarik kesimpulan.

Dari hasil penelitian terdapat faktor-faktor dari turunnya temperatur dari ruang pendingin makanan yaitu, terjadinya kebocoran freon pada pipa coil evaporator, terlalu banyak minyak lumas di dalam compressor, kotornya oil separator, banyaknya uap air yang berada pada ruang pendingin, seringnya terbuka pintu ruang pendingin, kotornya condenser dan juga kurangnya kapasitas air pendingin pada condenser. Dan berdasarkan penelitian yang dilakukan terdapat dampak dari turunnya temperatur pada ruang pendingin makanan akan menyebabkan turunnya temperatur pada indikator ruang pendingin, terdapatnya bunga-bunga es pada pipa coil evaporator yang disebabkan karena kurangnya freon pada sistem. Serta kerja compressor yang berjalan terus menerus. Untuk menjaga agar temperatur pada ruang pendingin tetap optimal yaitu melakukan perawatan pada komponen-komponen mesin pendingin tersebut secara rutin sesuai dengan instruction manual book.
\end{abstract}

Kata kunci : Temperatur, Pendingin Makanan, Fault Tree Analysis.

\section{PENDAHULUAN}

MT. Bauhinia dalam pelayaran dari loading di Singapura lalu perjalanan ke China untuk melakukan kegiatan discharging, mendapat permasalahan yaitu turunnya temperatur pada ruang pendingin makanan dan apabila masalah ini tidak ditindaklanjuti dapat berakibat fatal bagi ketahanan dan kualitas dari bahan-bahan makanan di kapal. Langkah yang diambil yaitu mematikan mesin pendingin makanan tersebut. Setelah mesin pendingin makanan mati, para masinis dan crew mesin lainnya mengecek kondisi mesin pendingin makanan. Belum diketahui faktor penyebab yang mengakibatkan turunnya temperatur pada ruang pendingin makanan. Hal ini sangat mempengaruhi kondisi persediaan makanan selama masa pelayaran yang harus dilakukan pengambilan keputusan untuk mengatasinya agar dapat dilakukan upaya penanggulangan selanjutnya.

Tujuan penelitian ini adalah untuk mengetahui faktor-faktor apa saja yang mengakibatkan turunnya temperatur pada 
ruang pendingin makanan serta dampak dari turunnya temperatur pada ruang pendingin makanan dan juga upaya yang dilakukan untuk mengatasi turunnya temperatur pada ruang pendingin makanan.

\section{METODE PENELITIAN}

Metode penelitian yang digunakan dalam penelitian ini adalah metode fault tree analysis yang merupakan satu dari teknik yang paling sering digunakan dalam resiko analisis adalah model pohon kesalahan. Analisa pohon kesalahan (FTA) dapat digunakan untuk mengidentifikasi subsistem yang paling penting untuk pengoperasian pada sebuah sistem yang telah diberikan atau untuk menganalisa bagaimana kejadian tak terkira. Fault tree analysis merupakan metode analisa, dimana terdapat suatu kejadian yang tidak diinginkan disebut undersired event terjadi pada sistem, dan yang ada untuk menemukan semua cara yang mungkin terjadi yang mengarah pada terjadinya undersired event tersebut.

Penelitian ini menggunakan dua sumber data yakni data primer dan data sekunder. Data primer yang digunakan dalam penelitian ini adalah data diperoleh secara langsung dengan melakukan observasi atau mengamati aktivitas-aktivitas tentang penyebab turunnya temperatur pada ruang pendingin makanan dan wawancara langsung dengan para masinis MT. Bauhinia. Data sekunder yang digunakan dalam penelitian ini adalah Engine Log Book.

\section{HASIL DAN PEMBAHASAN}

\section{A. Gambaran Umum Objek Penelitian}

Spesifikasi dari mesin pendingin makanan di MT. Bauhinia yaitu:

$\begin{array}{ll}\begin{array}{l}\text { Refrigeranting } \\ \text { machine: }\end{array} & \text { DAIKIN } \\ \text { Refrigerant: } & \text { Model No. RKS - 3F } \\ \text { Cooling } & \text { Cooling Is Direct } \\ \text { Methode: } & \text { Expansion System } \\ \text { Defrost } & \text { Hot Gas Circuit By } \\ \text { Methode: } & \text { Manually Controlled } \\ \text { Operation } & \text { Refrigerating machine } \\ \text { method: } & \text { is operated }\end{array}$

automatically by thermostats in each Ref. Provision chamber

Safety device: Dual pressure switch Daikin 20582SE - F

Compressor: High speed multicylinder type Horizontal shell \& bare

Condenser: tubetype cooling surface area $0.857 \mathrm{~m}^{2}$

Expantion valve:

TX2

Safety valve:

OSV12B - 21 A

Oil separator:

Vertical shell type with automatic oil return

\section{Sumber: Intruction manual book}

Salah satu penunjang yang sangat vital dan berhubungan dengan ketahanan bahanbahan makanan di atas kapal. Bahan makanan itu harus tetap berkualitas meskipun dalam penyimpanan yang lama. Bahan makanan itu tidak banyak yang rusak atau busuk. Apabila kebutuhan akan bahan makanan itu terpenuhi berapa lama kita akan berlayar, kita tak perlu khawatir akan kelaparan di atas kapal. Dan juga bila makanan tercukupi, kita akan punya tenaga dan kemampuan untuk tetap berkarya dengan baik.

Agar bahan makanan tersebut tetap berkualitas dalam penyimpanan, kita memerlukan alat yang mendukungnya. Kita perlu memiliki mesin pendingin makanan yang memenuhi standar kerja. Untuk sayur dan buah yang berkualitas, tentu sayur dan buah tersebut masih segar, tidak layu atau tidak susut dan rasanya tidak berubah. Untuk daging dan ikan yang masih baik adalah tidak lembek, tidak busuk dan saat disimpan dapat membeku seluruhnya dan bila perlu sampai mengkristal. Agar buah dan sayur tersebut tetap baik, kita perlu suhu penyimpanan antara $10^{\circ} \mathrm{C}$ sampai $12^{\circ} \mathrm{C}$, dan bila perlu sampai $4^{\circ} \mathrm{C}$, untuk penyimpanan daging dan ikan kita perlu suhu kerja antara $-12^{\circ} \mathrm{C}$ sampai $-18^{\circ} \mathrm{C}$. Bila untuk mengkristalkannya kita perlu suhu sampai $-30^{\circ} \mathrm{C}$. Sumber dari uraian di atas sesuai dengan instruksi manual book. 
Yulian Harjuansyah ${ }^{\mathrm{a}}$, Abdi Seno ${ }^{\mathrm{b}}$, Okvita Wahyuni ${ }^{\mathrm{c}}$

Agar mesin pendingin makanan dapat bekerja memenuhi suhu yang disyaratkan tersebut, perlu adanya perawatan yang baik oleh masinis di atas kapal, perawatan itu terdiri dari komponen utama dan komponen pendukung antara lain: compressor, condenser, fan, oil separator, dryer, expantion valve, evaporator, sistem saluran refrigerant dan sistem kontrol listriknya. Alat-alat tersebut harus dirawat dengan konsisten sesuai dengan instruction manual book. Atau dengan memperhatikan setiap jam jaga, bila ada kelainan segera diambil tindakan untuk mencegah terjadinya kerusakan fatal. Karena apabila sampai terjadi kerusakan fatal akan merugikan bagi seluruh awak kapal dan juga perusahaan. Dengan kerusakan fatal akan mengakibatkan jam kerja awak kapal harus ekstra dan biaya produksi untuk operasional kapal dan perawatan.

Manometer isap menunjukkan tekanan $2 \mathrm{~kg} / \mathrm{cm} 2$ dan manometer tekan $10 \mathrm{~kg} / \mathrm{cm} 2$. Jumlah freon $1 / 2$ dari gelas duga, jumlah minyak lumas $3 / 4$ dari gelas duga. Suhu daging $-6^{\circ} \mathrm{C}$ dan suhu ruangan sayur $16^{\circ} \mathrm{C}$, Setelah dilakukan pengamatan 4 jam sekali setiap pergantian jam jaga, ternyata level freon berkurang. Hal itu dapat dilihat pada gelas duga. Selanjutnya langkah yang diambil KKM dan masinis jaga yaitu mematikan mesin pendingin makanan tersebut. Setelah mesin pendingin makanan mati KKM serta masinis jaga dan crew mesin lainnya mengecek kondisi mesin pendingin makanan tersebut.

\section{B. Analisis hasil penelitian}

1. Faktor yang mengakibatkan turunnya temperatur pada ruang pendingin makanan.

Terdapat beberapa faktor yang menyebabkan turunnya temperatur pada ruang pendingin makanan diantaranya adalah terjadinya kebocoran freon dari pipa evaporator. Terdapat bunga-bunga es pada pipa evaporator. Masuknya minyak lumas ke dalam sistem freon juga dapat mempengaruhi turunnya temperatur pada ruang pendingin makanan, hal ini biasanya disebabkan karena terlalu banyaknya minyak lumas di dalam compressor, Dan juga kotornya oil separator. Turunnya temperatur pada ruang pendingin makanan juga disebabkan karena kurang optimalnya proses kondensasi yang disebabakan karena condenser yang kotor dan juga kurangnya kapasitas air pendingin pada condenser.

2. Dampak dari turunnya temperatur pada ruang pendingin makanan.

Dengan melakukan analisis komponensial tehadap fokus, maka pada tahap ini telah menemukan karakteristik, perbedaan dan kesamaan antar kategori, serta menemukan hubungan antara satu kategori dengan kategori lainnya. Dengan melakukan observasi dengan melihat keadaan yang terjadi setelah turunnya temperatur pada ruang pendingin makanan, penulis melihat dampak langsung yang terjadi di atas kapal MT. Bauhinia yaitu compressor jalan terus menerus, temperatur pada manometer turun, terjadi bunga-bunga es pada pipa evaporator. Dalam hal ini mesin pendingin akan berkurang ketahanannya bahan dari komponen mesin pendingin tersebut jika beroperasi secara terus menerus melebihi standar kerjanya.

3. Upaya mengatasi turunnya temperatur pada ruang pendingin makanan.

Upaya yang dilakukan di atas kapal terhadap turunnya temperatur pada ruang pendingin makanan adalah mematikan sementara refrigerant machine, setelah itu melakukan pembersihan pada condenser, membersihkan oil separator, melakukan pengelasan pada sistem pipa yang bocor dan mengurangi jumlah minyak lumas yang terlalu banyak di dalam compressor.

\section{Pembahasan masalah}

Untuk menganalisis turunnya temperatur pada ruang pendingin makanan, digunakan metode fault tree 
analysis dan memerlukan suatu diagram yang disebut dengan pohon kesalahan. Permasalahan yang akan dijelaskan, disusun dalam bagian yaitu turunnya temperatur pada ruang pendingin makanan sebagai top event, atau masalah utama yang akan dijabarkan akan menghasilkan intermediate event, basic event dan cut set.

1. Faktor-faktor yang mengakibatkan turunnya temperatur pada ruang pendingin makanan.

\section{a. Top event}

Dalam penelitian skripsi ini didapati top event dari penyebab turunnya temperatur pada ruang pendingin makanan. Berikut adalah gambar diagram pohon kesalahan dari penyebab turunnya temperatur pada ruang pendingin makanan, akan dijelaskan pada setiap faktor-faktor yang menyebabkan top event terjadi freon.

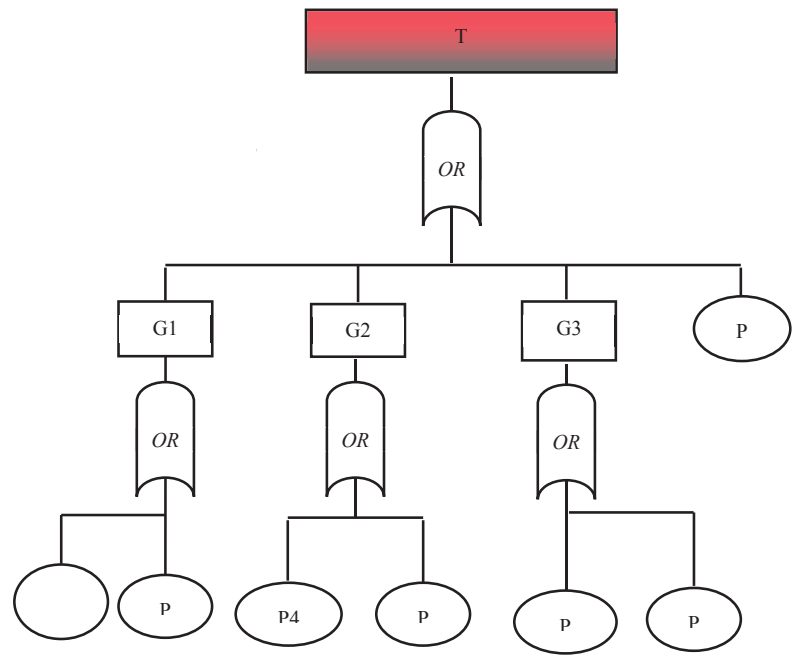

Gambar 4.1

Penyebab turunnya temperatur pada ruang pendingin makanan

Keterangan:

T: Penyebab turunnya temperatur pada ruang pendingin makanan

G1: Masuknya minyak lumas ke dalam sistem

P2: Teralu banyak minyak lumas di dalam Compressor

P3: Kotornya oil separator

G2: Terdapat bunga es pada pipa-pipa coil evaporator
P4: Banyaknya uap air yang berada pada ruang pendingin

P5: Seringnya terbuka pintu ruang pendingin

G3: Kurang optimalnya proses kondensasi

P6: Kotornya condenser

P: Kurangnya kapasitas air pendingin pada Condenser

P1: Terjadinya kebocoran freon pada pipa evaporator

b. Basic event

1) Terlalu banyak minyak lumas di dalam compressor

Dalam sistem mesin pendingin makanan fungsi dari minyak lumas adalah untuk melumasi bagian dari komponen-komponen compressor. Minyak lumas tersebut ditampung di dalam karter (kotak engkol) compressor. Bagian-bagian yang dilumasi antara lain: bearing, poros engsol, silinder liner dan bagianbagian lain yang saling bergesekan. Agar minyak pelumas tersebut dapat beredar ke bagian-bagian dan menjaga agar komponen-komponen pada compressor mempunyai ketahanan yang lebih lama, pada compressor dipasang pompa untuk mengedarkan minyak lumas. Tetapi pada kenyataan operasional kerja mesin pendingin, minyak lumas tersebut dapat juga menjadi penyebab terjadinya turunnya temperatur. Pada mesin pendingin makanan. Hal ini terjadi apabila penambahan minyak lumas yang berlebihan, minyak lumas ikut beredar ke dalam sistem freon. Bila hal ini terjadi aliran freon dalam sistem terganggu, karena minyak lumas sangat beda karakteristiknya dengan freon. Dengan ikut beredarnya minyak lumas ke dalam sistem freon akan mengganggu proses pemindahan panas pada proses penguapan di evaporator.

2) Kotornya oil separator

Faktor utama penyebab yang paling dominan minyak lumas ikut 
Yulian Harjuansyah ${ }^{\mathrm{a}}$, Abdi Seno ${ }^{\mathrm{b}}$, Okvita Wahyuni ${ }^{\mathrm{c}}$

beredar bersama freon ke dalam sistem adalah kotornya oil separator. Oil separator berfungsi untuk memisahkan bahan-bahan padat dan kotoran yang ikut terbawa di dalam minyak pelumas. Minyak pelumas yang banyak mengandung kotoran/ endapan padat akan mempengaruhi di dalam proses penyaringan, karena akan mempercepat menutupi celah-celah saringan, jika hal ini terus terjadi maka minyak lumas dalam tabung oil separator (pemisah minyak) levelnya akan bertambah semakin tinggi hingga mencapai saluran freon. Apabila minyak lumas sudah sampai pada saluran freon maka minyak lumas akan ikut beredar ke dalam sistem freon. Dengan adanya minyak lumas yang ikut beredar akan menyebabkan saluran pipa kapiler akan menyempit, dan akan tejadi gumpalan-gumpalan minyak lumas. Hal inilah yang mengganggu sirkulasi freon.

3) Banyaknya uap air yang berada pada ruang pendingin

Banyaknya uap air yang berada pada ruang pendingin berasal dari uap bahan makanan yang didinginkan karena bahan makanan tersebut akan melepaskan panas dan panas tersebut akan diserap oleh pipa coil evaporator karena adanya sirkulasi udara dingin setelah melewati pipa coil evaporator di dalam ruang dingin.

4) Seringnya terbuka pintu ruang pendingin

Seringnya membuka tutup pintu ruang pendingin dan membiarkan pintu terbuka terlalu lama dapat mengakibatkan udara luar masuk dalam ruang dingin, yang mana udara luar tersebut membawa kandungan air yang menyebabkan timbulnya bunga-bunga es pada pipa coil evaporator.
5) Kotornya condenser

Kotornya condensor biasanya disebabkan karena tertutupnya lumpur dan kotoran pada pipa-pipa condenser. yang menyebabkan proses pemindahan panas dari freon ke air pendingin terganggu, karena luas permukaan pipa tertutup kotoran. Buntunya pipa condenser diakibatkan kurang terawatnya condenser atau karena masuk perairan dangkal seperti masuk sungai. Oleh sebab itu perlu dilakukan pembersihan secara berkala terhadap condenser tersebut.

6) Kurangnya kapasitas air pendingin pada condenser

Untuk mencairkan freon hasil kerja dari compressor, maka freon dalam keadaan gas harus dikondensasikan. Supaya mendapatkan freon cair bertekanan tinggi. Agar proses kondensasi dapat maksimal, hal yang harus terpenuhi adalah kapasitas dari air pendinginnya. Apabila proses kondensasinya terganggu juga akan sangat berpengaruh sekali pada suhu ruang pendingin makanan tersebut. Oleh sebab itu pengecekan terhadap kapasitas air pendingin harus dilakukan secara rutin, dengan memperhatikan banyak sedikitnya air pendingin yang masuk di dalam condenser.

7) Terjadi kebocoran freon pada pipa evaporator

Kebocoran freon pada pipa bisa terjadi kapanpun tanpa diduga. Hal ini disebabkan karena karena kondisi pipa yang sudah keropos dan tipis. Kebocoran freon pada pipa menyebabkan mesin pendingin tidak dapat bekerja dengan baik. Karena jumlah kapasitas freon yang berkurang dan tidak sesuai dengan kodisi normalnya. Jika terjadi kebocoran freon pada pipa, pada sistem akan mengakibatkan turunnya temperatur pada ruang pendingin makanan. 
2. Dampak yang terjadi apabila turunnya temperatur pada ruang pendingin makanan

a. Compressor jalan terus menerus

Fungsi compressor pada mesin pendingin makanan adalah bekerja sebagai pompa untuk mengsirkulasikan freon dalam siklus pendinginan dengan tujuan mempertahankan temperatur dingin dalam ruangan dan untuk mencapai ini compressor bisa jadi akan bekerja secara auto stop. Namun apabila compressor bekerja secara terus menerus bisa jadi disebabkan karena bahan pendingin freon tidak cukup untuk mendinginkan freon dari evaporator. Jika hal ini terus dibiarkan maka compressor mesin pendingin akan mengalami kerusakan, karena jam kerjanya melebihi batas normalnya. Dan akan mengakibatkan ketahanan dari komponen compressor tersebut akan berkurang, karena melebihi standar kerjanya.

b. Banyaknya bunga es pada pipa-pipa evaporator

Banyaknya bunga es pada pipapipa evaporator biasanya disebabkan karena kurangnya freon, Hal ini juga bisa disebabkan juga karena faktor dari dalam sistem dan faktor dari luar sistem. Faktor dari dalam dipengaruhi oleh tingkat kelembaban udara yang akan mempengaruhi kandungan air di dalam udara tersebut, dan juga berasal dari uap bahan makanan yang didinginkan karena bahan makanan tersebut akan melepaskan panas dan panas tersebut akan diserap oleh pipa coil evaporator. Jadi banyak sedikitnya jumlah bahan makanan yang disimpan di ruangan pendingin juga mempengaruhi pembentukan bunga es tersebut. Jika lapisan bunga es tersebut makin menebal maka akan dapat mengakibatkan terganggunya proses penyerapan panas oleh freon di dalam pipa coil evaporator.
Akibatnya persedian makanan di atas banyak yang membusuk dan tidak tahan lama. Hal ini dapat mengganggu kesejahteraan dan kesehatan bagi seluruh awak kapal di atas kapal.

c. Indikator temperatur pada ruang pendingin makanan turun

Akibat dari kurangnya freon di dalam sistem maka temperatur pada ruang pendingin makanan juga akan turun, oleh sebab itu level freon di dalam sistem harus sesuai dengan batas normalnya. Agar temperatur pada ruang pendingin makanan tetap normal. Namun jika temperaturnya tidak normal maka akan mempengaruhi ketahanan bahan makanan di atas kapal, dan apabila ini terus dibiarkan maka persediaan makanan diatas kapal akan terganggu. Dan akibatnya persedian makanan di atas kapal banyak yang membusuk dan layu.

3. Upaya yang dilakukan untuk mengatasi turunnya temperatur pada ruang pendingin makanan

a. Upaya untuk mengatasi kurang optimalnya proses kondensasi

Apabila temperatur pada ruang pendingin makanan turun. Bisa jadi disebabkan karena proses kondensasi tidak bekerja dengan baik. ini dikarenakan condensor yang kotor. Tindakan yang harus dilakukan adalah membersihkan condenser tersebut.

Langkah-langkah membersihkannya yaitu dengan:

1) Mematikan compressor secara otomatis, dengan melakukan pumping down;

2) Mematikan pompa air pendingin untuk kondensasi;

3) Menutup katup masuk dan keluarnya air pendingin yang menuju dan dari condenser;

4) Membuka cover penutup condenser; 
Yulian Harjuansyah ${ }^{\mathrm{a}}$, Abdi Seno ${ }^{\mathrm{b}}$, Okvita Wahyuni ${ }^{\mathrm{c}}$

5) Melakukan pembersihan condenser dengan membersihkannya pada setiap lubang yang dilalui air pendingin dengan menggunakan stik pembersih;

6) Mengganti dengan yang baru anti korosif/ zink anode yang terpasang pada cover-nya.

Apabila seluruh lubang pendingin sudah dibersihkan semua maka cover-nya dapat ditutup kembali. Setelah cover-nya tertutup buka katup-katup air pendingin yang tertutup dan jalankan pompa air pendinginnya. Setelah air pendingin berjalan normal hidupkan compressor secara otomatis, dengan membuka katup (stop valve) yang dipasang di bawah condenser.

b. Upaya mengatasi terdapat bungabunga es pada pipa coil evaporator

Untuk mengatasi permasalahan yang disebabkan oleh terdapatnya bunga-bunga es pada pipa coil evaporator adalah dengan melakukan defrosting. Ada dua cara defrosting yaitu dengan cara semi otomatis dan otomatis.

\section{1) Defrosting dengan menggunakan cara semi otomatis}

Semi automatic defrost adalah mencairkan bunga-bunga es didalam pipa coil evaporator dengan menekan control defrost sehingga hubungan listrik ke motor compressor terputus mengakibatkan elemen pemanas (heater defrost evaporator) bekerja memanaskan evaporator. Setelah bunga-bunga es di pipa coil evaporator mencair semuanya, suhu di coil evaporator akan naik dan secara otomatis kontak listrik di pengatur suhu (thermostat) akan berhubungan lagi dan compressor motor bekerja mendinginkan kembali.

Jadi waktu bunga-bunga es di coil evaporator telah menjadi tebal, kita hanya perlu menekan tombol kontrol pengatur defrost dan selanjutnya akan terjadi kerja mencairkan bunga-bunga es di coil evaporator. Dengan menekan tombol control defrost, elemen pemanas listrik (heater) dialiri arus listrik. Mengakibatkan di coil evaporator bunga-bunga es dicairkan. Setelah bunga-bunga es di coil evaporator mencair semuanya, suhu coil evaporator akan naik. Gas di dalam pipa kapiler dari bulb pengatur defrost akan bertambah tekanannya, sehingga cukup kuat untuk mendorong kontak listrik. Hubungan listrik ke elemen pemanas listrik terputus, compressor motor bekerja mendinginkan ruang pendingin kembali.

2) Defrosting secara otomatis (automatic defrost)

Pada umumnya kapal-kapal yang modern mesin pendingin makanan dilengkapi dengan sistem defrost secara otomatis. Mesin pendingin semacam ini memang pada bagian ruangan pendingin makanan tidak akan terjadi bungabunga es yang tebal, karena mencairkan bunga-bunga es di bagian coil evaporator dimulai dan selesainya secara otomatis. Automatic defrost adalah mencairkan bunga-bunga es di bagian coil evaporator secara otomatis. Kita tidak perlu menekan atau memutar tombol untuk membuat defrost. Setelah mencairkan bunga-bunga es di coil evaporator selesai, proses mendinginkan kembali berlangsung akan terjadi dengan sendirinya secara otomatis.

Biasanya defrost secara otomatis menggunakan timer. Defrost timer adalah untuk mengatur jarak, waktu terjadinya pencairan bunga-bunga es di coil evaporator pada selang atau jarak waktu tertentu. Defrost timer telah direncanakan agar dalam waktu 24 jam terjadi 3 atau 4 kali membuat 
defrost. Jadi dalam waktu 6 jam dari lamanya compressor berjalan sekali membuat defrost. Lama waktu defrost antara 12 menit sampai dengan 30 menit. Defrost timer ada juga yang setelah semua bungabunga es di coil evaporator mencair, memerlukan waktu tunggu selama 1,5 menit sampai dengan 3 menit sebelum compressor motor dan fan motor dapat bekerja kembali. Waktu tunggu tersebut maksudnya agar air dari bunga-bunga es yang mencair di bagian coil evaporator mempunyai kesempatan untuk mengalir keluar dari dalam cabinet ruangan pendingin.

c. Upaya mengatasi terlalu banyak minyak lumas dalam compressor crankcase

Untuk mengatasi permasalahan yang disebabkan oleh terlalu banyaknya minyak lumas adalah dengan mengurangi jumlah minyak yang ada dalam karter.

\section{KESIMPULAN}

Dari uraian dan bahasan yang telah diuraikan di atas maka dapat ditarik kesimpulan bahwa faktor yang menyebabkan turunnya temperatur pada ruang pendingin makanan yaitu terjadinya kebocoran freon pada pipa coil evaporator, terlalu banyak minyak lumas di dalam compressor, kotornya oil separator, banyaknya uap air yang berada pada ruang pendingin, seringnya terbuka pintu ruang pendingin, kotornya condenser dan juga kurangnya kapasitas air pendingin pada condenser.

Terdapat dampak yang terjadi akibat turunnya temperatur pada ruang pendingin makanan yaitu turunnya temperatur pada indikator ruang pendingin, munculnya bungabunga es pada pipa coil evaporator yang disebabkan karena kurangnya freon pada sistem. Serta kerja compressor yang berjalan terus menerus.

Adapun upaya yang dilakukan adalah melakukan perawatan pada komponenkomponen mesin pendingin tersebut secara rutin sesuai dengan instruction manual book.

\section{DAFTAR PUSTAKA}

A.R. Trott. 2008. Refrigeration and Air Conditioning. USA

G. F. Hundy. 2016. dkk, Refrigerator, Air Conditioning and Heat Pumps. USA

Kristiansen. 2005. Metode Fault Tree Analysis. Indonesia

Kuo, Chengi. 2007. Kelebihan dan Kekurangan Fault Tree Analysis. Indonesia

Moleong, Lexy J. 2015. Metode Penelitian Kualitatif. Bandung: PT Remaja Rosdakarya

Manual book. 1997. Daikin Condensing Unit. Japan

Sugiono. 2009. Metode Penelitian Bisnis. Jakarta: ALFABETA

Tim Penyusun Politeknik Ilmu Pelayaran Semarang. 2016. Panduan penyusunan skripsi Diploma IV. Semarang

Widoyoko, Eko P. 2012. Teknik Penyusunan Instrumen Penelitian. Yogyakarta: Pustaka Pelajar. 